\title{
Variation and mechanisms of clastic reservoir quality in the Paleogene Shahejie Formation of the Dongying Sag, Bohai Bay Basin, China
}

\author{
Zhang Qin ${ }^{1,2 *}$, Zhu Xiaomin ${ }^{1,2}$, Ronald J Steel ${ }^{3}$ and Zhong Dakang, \\ ${ }^{1}$ College of Geosciences, China University of Petroleum, Beijing 102249, China \\ ${ }^{2}$ State Key Laboratory of Petroleum Resource and Prospecting, China University of Petroleum, Beijing 102249, China \\ ${ }^{3}$ Department of Geological Sciences, The University of Texas at Austin, Austin, TX, 78712, USA \\ (C) China University of Petroleum (Beijing) and Springer-Verlag Berlin Heidelberg 2014
}

\begin{abstract}
Reservoir quality varies greatly in the Shahejie Formation in the Dongying Sag. It is essential to analyze the variation and mechanisms of reservoir quality for determining the controlling factors based on cores, porosity measurements and fluid inclusion techniques and so on. The sandstones in the fluvial, (fan) delta-front have the best reservoir quality due to the depositional conditions mechanically controlling the petrology configuration and the primary porosity, and chemically influencing the diagenesis and development of secondary pores. The activity of the boundary faults and the sedimentary facies dominate the variation of reservoir quality in different areas and intervals. The reservoir quality varies with the position of sandstone beds in different vertical models of sandstone and mudstone. This mainly arose from the strong cementation or strong dissolution in the sandstone caused by the diagenesis evolution of adjacent mudstone. With higher oil saturation reservoir quality is better because the hydrocarbon charge favors dissolution and restricts cementation. Diagenesis, depositional conditions and tectonic setting are the key controls of reservoir quality in the Shahejie Formation of the Dongying Sag.
\end{abstract}

Key words: Reservoir quality variation, clastic reservoir quality, hydrocarbon charge, vertical models of sandstone and mudstone, controlling factor

\section{Introduction}

Reservoir quality is one of the key controls on prospectivity during petroleum exploration and exploitation. Good or bad reservoir quality directly determines the hydrocarbon resources stored in the reservoir and controls the production capacity of the reservoir. On the other hand, it is important and essential to have a defined and detailed understanding of what controls reservoir quality to assist with the appraisal of the economic viability of petroleum discoveries (Hakimi et al, 2012; Gier et al, 2008). Therefore, it is important to determine the distribution of reservoirs and the controls on their quality not only at the early stage of exploration but at the mid-late stages of exploitation in the basin (Pu et al, 2013).

The Dongying Sag, located in the north of Shandong Province, China, is one of the secondary tectonic units of the Jiyang Depression, Bohai Bay Basin. It is a typical nonmarine half graben basin with a fault margin in the north and a ramp margin in the south. It is about $90 \mathrm{~km}$ long and 65 $\mathrm{km}$ wide, over an area of $5,700 \mathrm{~km}^{2}$. The sag consists of the

*Corresponding author. email: zhangqin@cup.edu.cn Received April 19, 2013
North Steep Slope Zone (NSSZ), the South Slope Zone (SSZ) and the Middle Area including Center Uplift Zone (CUZ) and several sub-depressions, namely the Niuzhuang, Lijin, Boxing and Minfeng Sub-depressions (Fig. 1) (Zhang et al, 2007). The Paleogene Shahejie Formation in this sag is divided into Sha-4 Member $\left(\mathrm{Es}_{4}\right)$, Sha-3 Member $\left(\mathrm{Es}_{3}\right)$, Sha-2 Member $\left(\mathrm{Es}_{2}\right)$ and Sha-1 Member $\left(\mathrm{Es}_{1}\right)$ from the bottom to the top, of which $\mathrm{Es}_{2}$ and $\mathrm{Es}_{3}$ have more data from cores, drilling, well logging and other geological test data and therefore can be taken as significant formations to be analyzed.

Although the Dongying Sag has been explored over the past five decades, and the clastic Paleogene reservoirs have already been well studied, including the distributions of sedimentary facies and diagenetic evolution (Zhang et al, 2007; Zhang, 2004), little is known about the variation of reservoir quality and the controls of the variation in the Shahejie Formation. When the vertical and horizontal distribution of reservoir quality was researched, visible differences were found with the variation of sedimentary facies, areas, stratigraphic intervals, oil saturation and positions in a vertical sequence of sandstone and mudstone. This paper analyzes and discusses the differences and their mechanisms based on large amounts of data related to reservoir properties in order to define the dominant factors of 


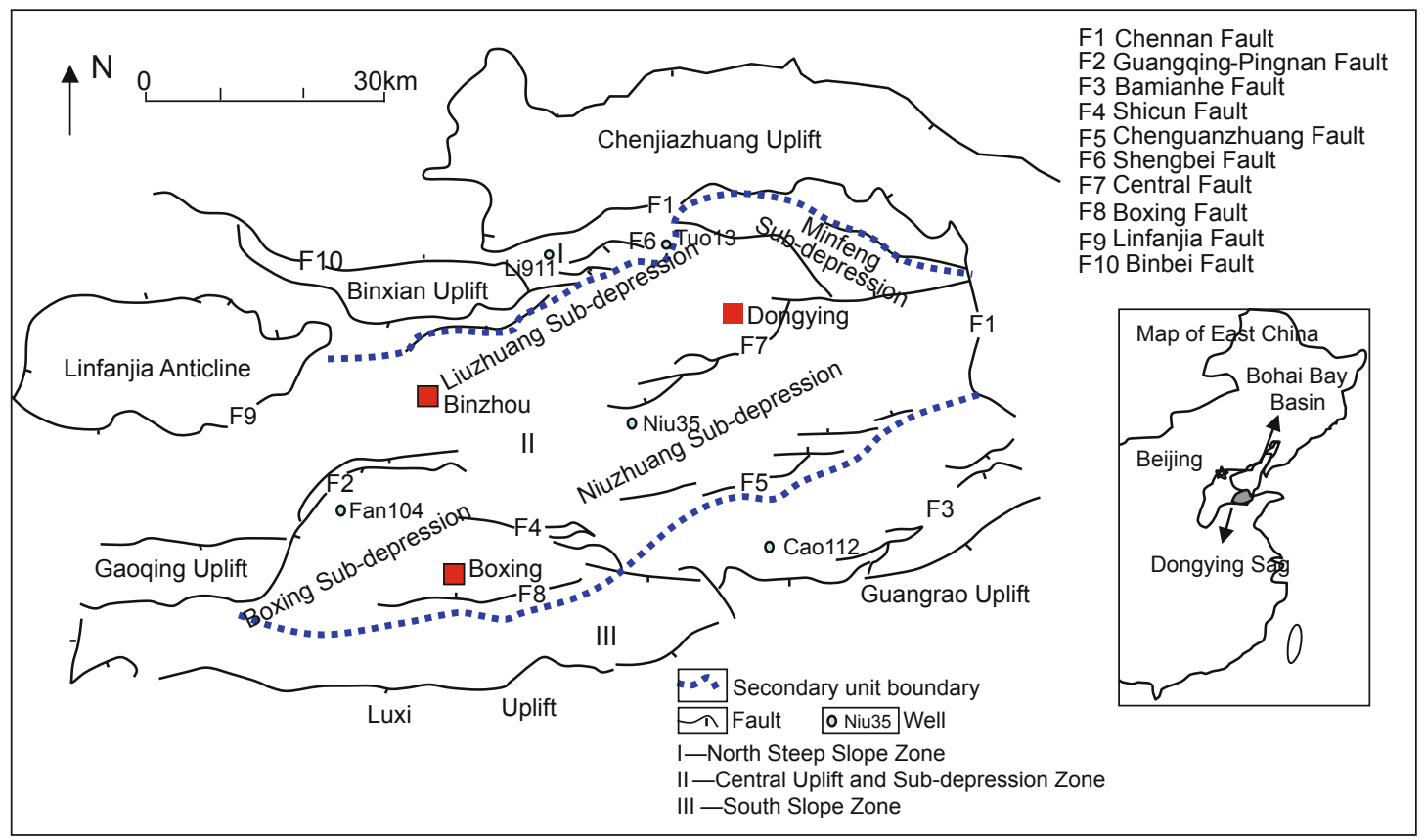

Fig. 1 Secondary structural units in the Dongying Sag (modified after Zhang, 2004)

clastic reservoir quality, which will provide more pertinent scientific guidance for the further exploration and exploitation of the Paleogene hydrocarbons here.

\section{Materials and methods}

Over 1,500 representative sandstone core samples in terms of facies and the range of present burial depth are selected from 26 principal wells (Table 1). Analysis and test items include thin sections, cast sections, scanning electron microscopy (SEM), cathode luminescence, X-ray diffraction and fluid inclusion techniques. In addition, numerous laboratory test data such as reservoir property parameters in 1,216 wells, 3,552 clay mineral data in 229 wells, mercuryinjection data in 7 wells are used in the research. All the samples and data are distributed in about 1,500 wells around the whole study area, and majority of them are from $\mathrm{Es}_{2}$ and $\mathrm{Es}_{3}$, while a few are from $\mathrm{Es}_{1}$ and $\mathrm{Es}_{4}$. Based on the analysis of the influences of depositional condition, regional setting, burial depth, different vertical sequences of sandstone and mudstone and fluid charge on the reservoir quality, the variation of clastic reservoirs in different conditions and mechanisms are defined clearly as follows.

\section{Variation of reservoir quality and mechanisms}

\subsection{Reservoir quality differences caused by depositional conditions}

The Shahejie Formation was mainly deposited in alluvial fan, fluvial fan, fan delta, turbidite fan, delta, deltafront slump turbidite fan and shore-shallow lake facies in the Dongying Sag (Li, 2004; Zhang et al, 2007). The distribution model of the sedimentary facies is showed in Fig. 2, namely fan delta and turbidite fan in NSSZ (such as
Table 1 Data and materials used in this research in the Shahejie Formation in the Dongying Sag

\begin{tabular}{ccc}
\hline Data and materials & Number of wells & Number of samples \\
\hline Core observations & 26 & 1350 meters \\
Test samples & 26 & 1500 \\
Thin sections & 32 & 514 \\
Cast sections & 47 & 464 \\
Cathode luminescence & 22 & 72 \\
Fluid inclusion analyses & 24 & 40 \\
Electron probe energy spectra & 19 & 45 \\
SEM & 22 & 486 \\
Clay mineral & 229 & 3552 \\
Parameters of reservoir properties & 1216 & 27000 \\
Vitrinite reflectance & 142 & 211 \\
Mercury-injection data & 7 & 110 \\
\hline
\end{tabular}

the south of Chenjiazhuang Uplift and Qingtuozi Uplift near the provenance area), fluvial and delta facies in SSZ, shoreshallow lake, delta and delta-front slump turbidite fan facies in CUZ, and delta facies in the eastern area.

Statistics of porosity and permeability show that reservoir quality changes greatly in the different sedimentary facies (Fig. 3). Reservoirs that deposited in fluvial, (fan) deltafront subaqueous distributary channels and mouth bars are of the best reservoir quality, while the reservoir qualities in a turbidite middle fan transitional zone and outer fans are worst. The average porosity and permeability in fluvial fans are up to $32 \%$ and $1,300 \times 10^{-3} \mu^{2}$, while they are only $11 \%$ and $3.5 \times 10^{-3} \mu^{2}$ in turbidite outer fans. 


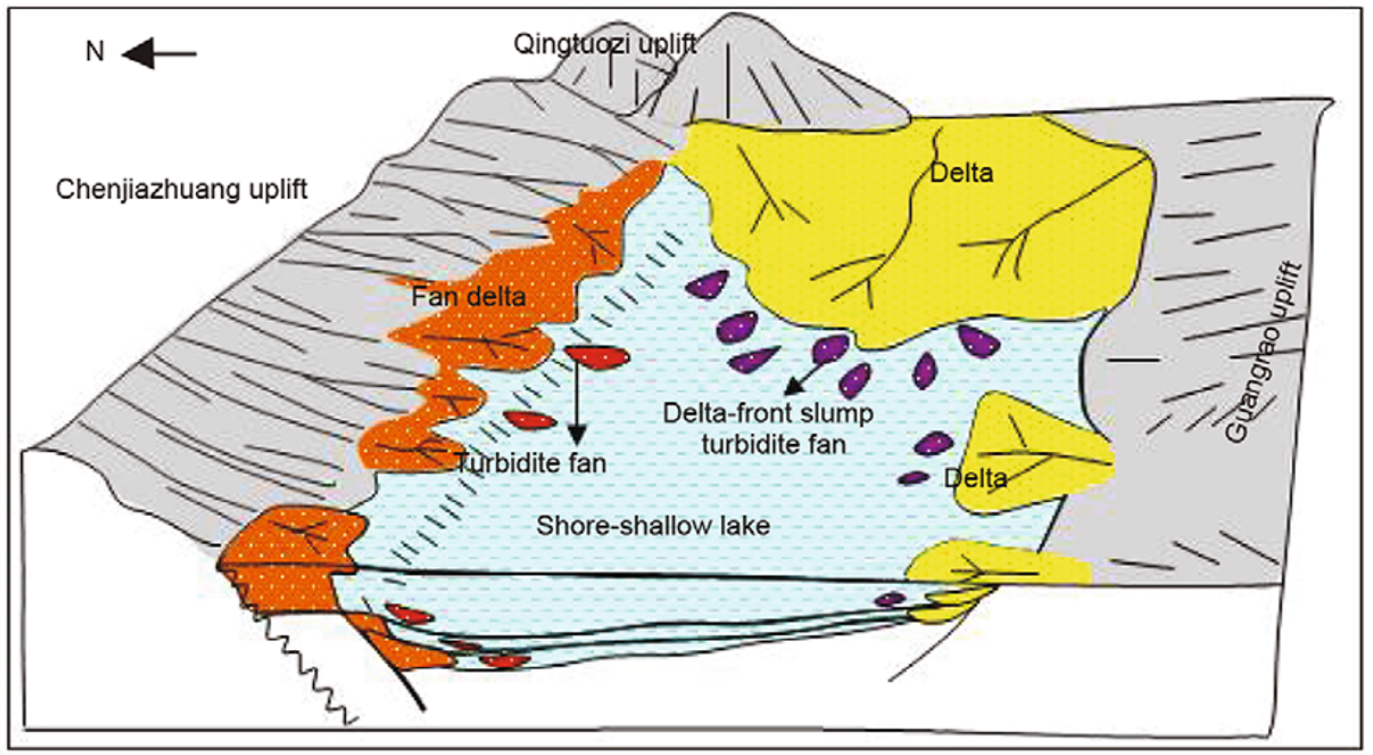

Fig. 2 Sedimentary model of the Shahejie Formation in the Dongying Sag

The above-mentioned differences are mainly determined by the different depositional conditions ( $\mathrm{Li}$ et al, 2012; Zhang et al, 2009), which are mainly embodied as controlling of the configuration of reservoir rocks and of the primary porosity (Zhu et al, 2008; Yu et al, 2011; Zhong and Zhu, 2008). When sandstone is characterized by a medium grain size and is wellsorted with little matrix, its primary porosity will be very high (Fig. 4) (Islam, 2010; Fattahpour et al, 2012). Otherwise, the reservoir quality tends to be poor (Xin et al, 2009). Reservoirs formed on high-energy depositional settings, such as deltafront subaqueous distributary channels and mouth bars, have the best petrology configuration and are most effective reservoirs (Özkan and Elmas, 2012).

At the same time, depositional settings further control the digenesis evolution of the reservoir to some degree (Kim et al, 2007), which influences the preservation of the primary pores and the development of secondary pores. For example, well-sorted sandstone with medium grain size, little matrix and rich rigid detrital quartz because of weak compaction will preserve many primary pores and allow unimpeded access of intergranular acid water resulting in the easy dissolution of soluble matter, such as calcite cement, limestone grain and feldspar. In addition, the high primary porosity contributes easily to the earlier cementation of calcite in most conditions, which will provide materials for further dissolution by the acid intergranular water released by the late mature organic matter in the adjacent mudstone (Fig. 5). Contrarily, the reservoir with a poor petrology configuration results in few primary pores inhibiting the steady flow of the intergranular acid water and providing little dissolvable intergranular cementation, and few secondary pores develop. Therefore, the diagenesis have different consequences that influence the reservoir quality in different sedimentary settings or by the micro-diagenetic differentiation in the same sedimentary setting.

It can be seen that the difference of reservoir quality in different sedimentary facies is caused commonly by the
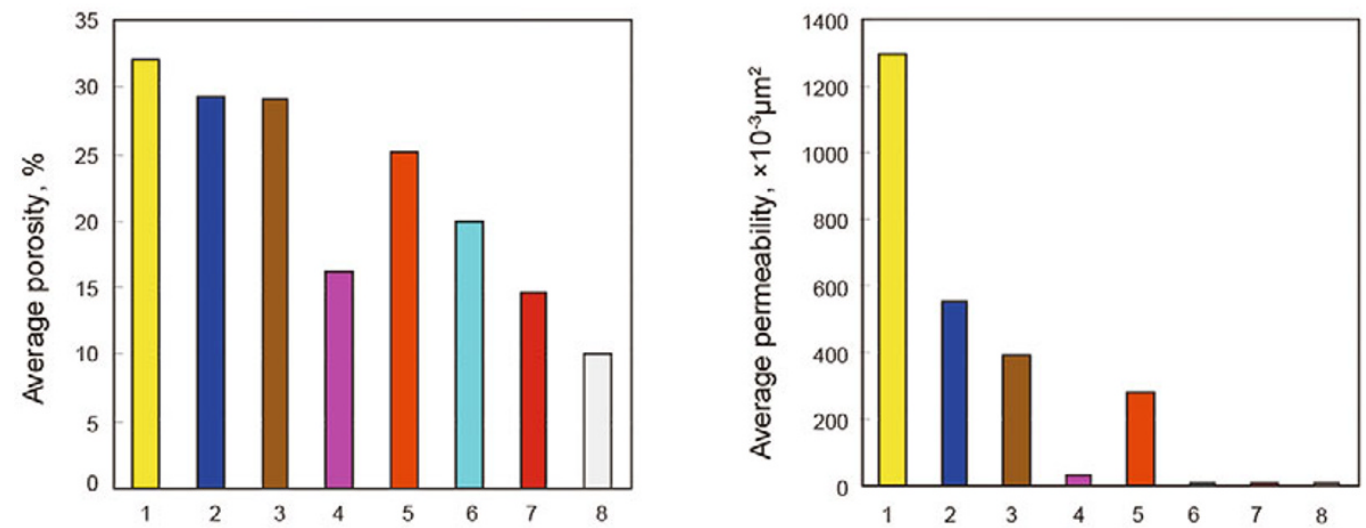

1 Fluvial; 2 Mouth bar; 3 Delta front subaqueous distributary channel; 4 Delta front mat-shape sandstone; 5 Fan delta front subaqueous distributary channel; 6 Turbidite middle fan braided channel;

7 Turbidite middle transitional zone; 8 Turbidite outer fan

Fig. 3 Distribution of the average porosity and permeability in different sedimentary microfacies of the Shahejie Formation in the Dongying Sag 


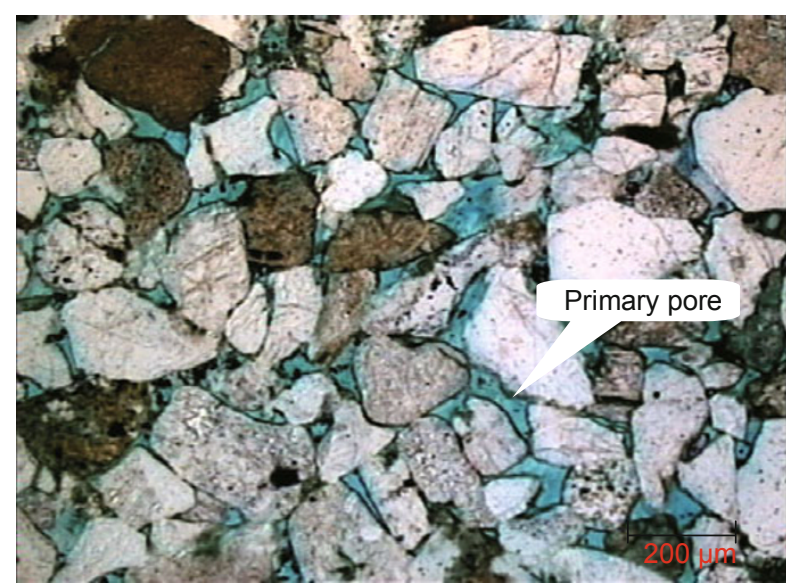

Fig. 4 Primary pores in the subaqueous distributary channel of the delta front in the Shahejie Formation in the Dongying Sag (Cast thinsection, Well Jin31, $\mathrm{Es}_{2}, 1300.2 \mathrm{~m}$ )

petrological configuration in different depositional conditions mechanically controlling the development of primary pores and by the different late diagenetic processes chemically controlling the development of secondary pores.

\subsection{Reservoir quality differences caused by location and stratigraphic intervals}

Curves of the porosity and permeability of the Shahejie Formation with varying depths (Fig. 6) and the contrast of the reservoir characteristics in different areas (Fig. 7) show that reservoirs in the CUZ have the highest porosity and permeability and contain more pores in the thin-section micrographs with a better reservoir quality than that in the NSSZ and SRZ in the shallow burial zone $(<3,300 \mathrm{~m})$, before late diagenesis B period. Reservoir quality in the NSSZ is better than that in the SRZ in the secondary pore zone $(1,500$ $2,500 \mathrm{~m}$ ), and outside this zone, reservoir quality is better in the SRZ than that in the NSSZ.

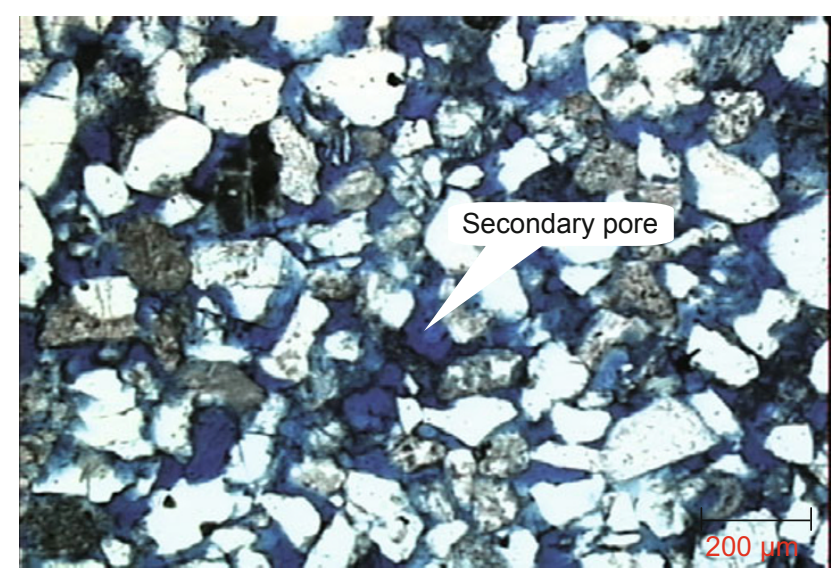

Fig. 5 Secondary pores generated by dissolution of the early calcite cement and other soluble matter in the mouth bar of the delta front in the Shahejie Formation in the Dongying Sag (Cast thin-section, Well Li911, $\left.\mathrm{Es}_{2}, 2019.25 \mathrm{~m}\right)$

These findings are caused mainly by the varying diagenesis evolution in different areas and partially and indirectly by the different sedimentary facies (Umar et al, 2011; Zhang et al, 2007; Mansurbeg et al, 2008; Sun et al, 2007). Faults are well developed over most of the CUZ and they remain active for a long time during the burial of the Shahejie Formation. They act as pathways for acidic water to dissolve the earlier calcite cements and feldspars so that secondary pores are best developed and most widespread (Fig. 7(b)). The NSSZ that subsided rapidly is close to the deep boundary fault zone that experienced intense recurrent activity. As a result, dissolution and cementation of sandstone are distributed zonally in depth, and secondary pores are better developed (Fig. 7(a)) with a second secondary pore zone near 3,000 m (Fig. 6). In contrast, secondary pores are not well developed in the SSZ due to absence of the active faults (Fig. 7(c)). Therefore, reservoir quality is best in the middle area at a similar burial depth of the secondary pore
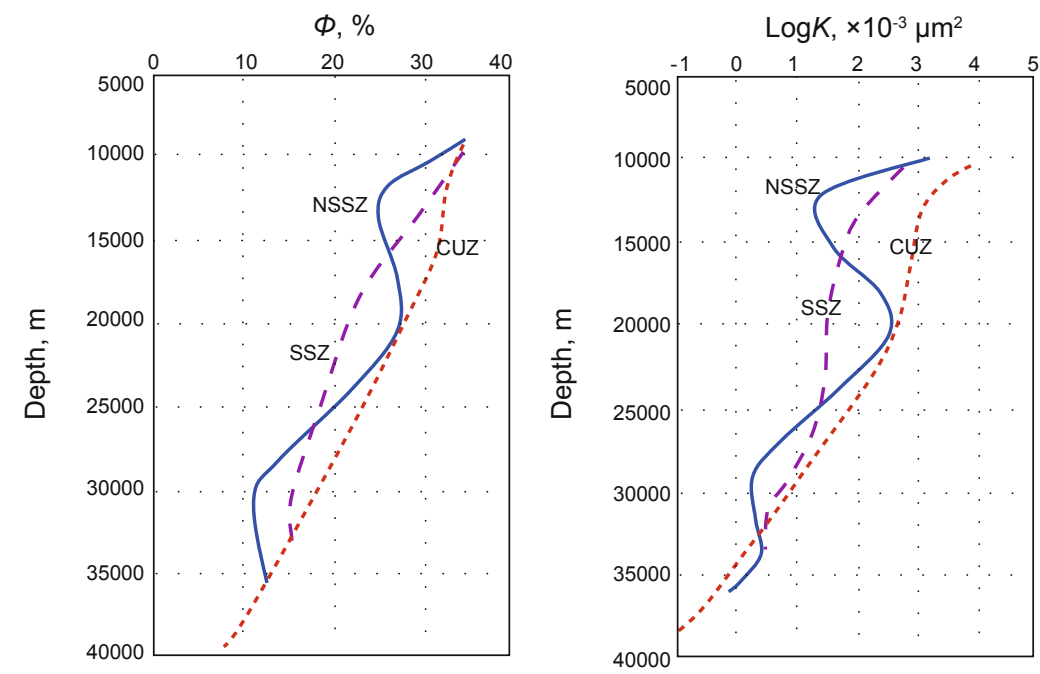

$\Phi$ : Porosity, K: Permeability

Fig. 6 Variation of porosity and permeability with the burial depth of the Shahejie Formation in different areas in the Dongying Sag 
distribution zone, and the NSSZ is moderate, while the SSZ tends to be the poorest. Outside the secondary pore zone, there mostly deposited deltaic and shore-shallow lake in the SSZ, while there mainly deposited fan delta and turbidite fan in the NSSZ with poorer reservoir petrologic configuration mostly developed, which leads to a better reservoir quality in SSZ than in NSSZ (Fig. 6).

In addition, according to porosity and permeability isolines, higher porosity and permeability existed in $\mathrm{Es}_{2}$,
$\mathrm{Es}_{3}{ }^{\text {Middle }}$ and $\mathrm{Es}_{4}{ }^{\text {Upper }}$, which was due to the burial depth and the stage of pore evolution (Zhu et al, 2009). $\mathrm{Es}_{2}$ was buried at a shallow depth and suffered only moderate compaction and cementation, and reservoirs with high porosity and permeability existed in the primary pore zone (Fig. 4), while $\mathrm{Es}_{3}{ }^{\text {Middle }}$ and $\mathrm{Es}_{4}{ }^{\text {Upper }}$ buried at a great depth suffered intense dissolution and favorable reservoirs existed in secondary pore zones. All these lead to the different distributions of good reservoir quality in the different formations.

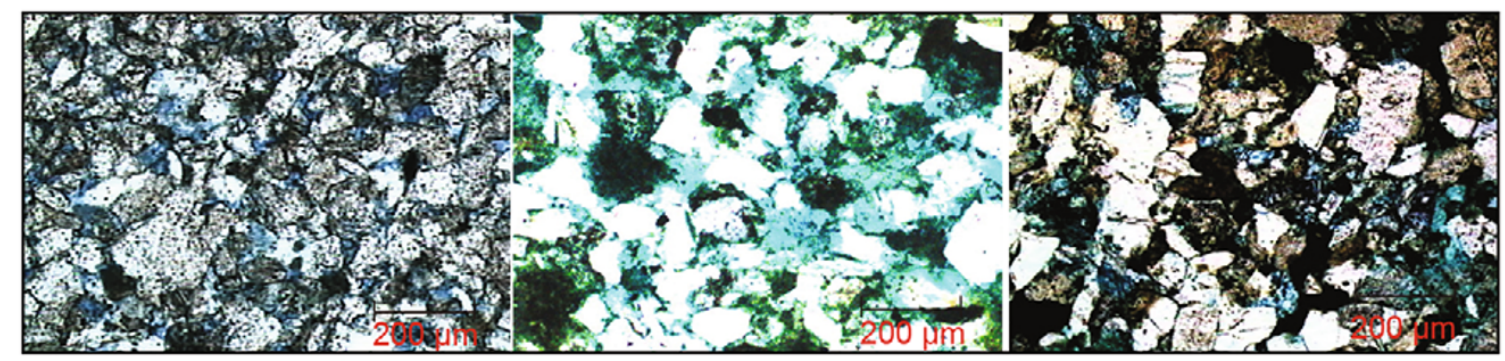

(a) North Steep Slope Zone (Well Bin425, 2667.7 m) (b) Central Uplift Zone (Well He155, 2981.39 m) (c) South Slope Zone

(Well Fan10, 2843.8 m)

Fig. 7 Distribution characteristics of pores in the secondary pore zone from north to south in the Dongying Sag

\subsection{Reservoir quality differences caused by positions of sandstone beds in different vertical successions of mudstone and sandstone}

Studies in recent years show that the diagenesis evolution of mudstone in different vertical successions of mudstone and sandstone greatly influenced the diagenesis of adjacent sandstones (Hou, 2007; Jiang et al, 2006; Gier et al, 2008), resulting in the strong anisotropy in the sandstone beds in the different vertical models and burial (Marcussen et al, 2010; Poursoltani and Gibling, 2011; Mallon and Swarbrick, 2008).

Five types of vertical successions of sandstone and mudstone are identified in the Dongying Sag (Fig. 8). Based on analyses of numerous test data, when the primary pores in sandstone are buried at less than $2,500 \mathrm{~m}$, the types of vertical successions of sandstone and mudstone have little influence on the reservoir quality in different positions of the sandstone beds (Büyükutku, 2006), although different parts of sandstone and mudstone encountered different diagenesis. At less than $1,650 \mathrm{~m}$, primary pores are preserved well. From 1,650 m to $2,500 \mathrm{~m}$, the dissolution at the uppermost and basal parts of the sandstone beds close to the mudstone is stronger than that in the middle part of the same sandstone, so the middle part of the sandstone tends to have a lower porosity.

When the depth is more than 2,500 m, there are four kinds of conditions in the different vertical sandstone and mudstone successions:

1) When the sandstone is encased in abundant mudstone (Type I) (Fig. 8), the porosity and permeability in sandstone are very low because of the intense cementation of carbonates (Fig. 9(c)).

2) When the thickness of sandstone is more than $1 \mathrm{~m}$ to 5 $\mathrm{m}$ (Type I), the reservoir quality of the inner sandstone begins to show variations (Fig. 9(a), (b)). Commonly, the upper and lower parts have poorer reservoir quality because of the higher carbonate cement (Fig. 9(a)), while the middle part of the sandstone has a better reservoir quality due to the lower carbonate cement (Fig. 9(b)).

3) In the conditions of mudstone overlying sandstone (Type II) (Fig. 9(d)) or sandstone overlying mudstone (Type III) (Fig. 9(e), (f)), the reservoir quality of the sandstone close to mudstone becomes significantly worse (Fig. 9(f)) than that

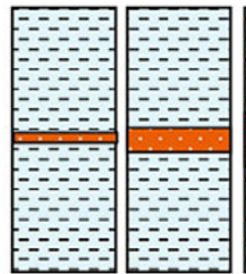

|

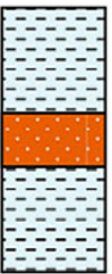

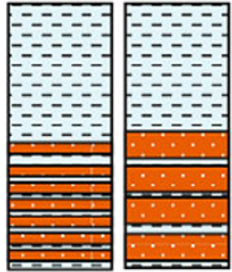

II

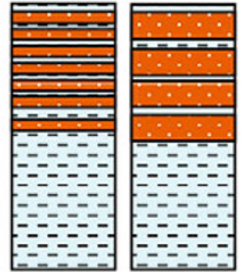

III

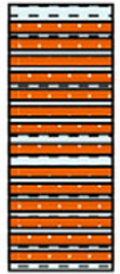

IV

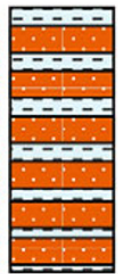

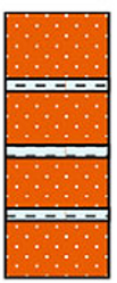

V

I: Sandstone encased in abundant mudstone; II: Mudstone overlying sandstone; III: Sandstone overlying mudstone; IV: Interbedded sandstone and mudstone; V: Mudstone encased in abundant sandstone

Fig. 8 Five types of vertical successions of mudstone and sandstone 
in the middle part (Fig. 9(d), (e)). The zone with low porosity and permeability is only about $0.5 \mathrm{~m}$ thick, and then the reservoir quality will become better further deep down to the inner zone and tends to be basically stable.

4) When the sandstone and mudstone combination is a thin or medium interbed (Type IV) (Fig. 9(g)), the mudstone has the same influence on the different positions of sandstone, resulting in homogeneous reservoir quality in the sandstone with porosity of $12 \%$ to $15 \%$.

The discoveries about the variation of reservoir quality in the above-mentioned different conditions involve the evolution of mudstone adjacent to the sandstone (Fig. 10) and the interaction between the mudstone and the boundary parts of the adjacent sandstone. When the sequences are buried less than $800 \mathrm{~m}$, masses of pore water in the formation is expelled and the type of vertical sequence models of mudstone and sandstone has little influence on the diagenesis and pore evolution of sandstone (Büyükutku, 2006), and large primary pores are well preserved in sandstone with little authigenic mineral precipitation (Fig. 10(a)).

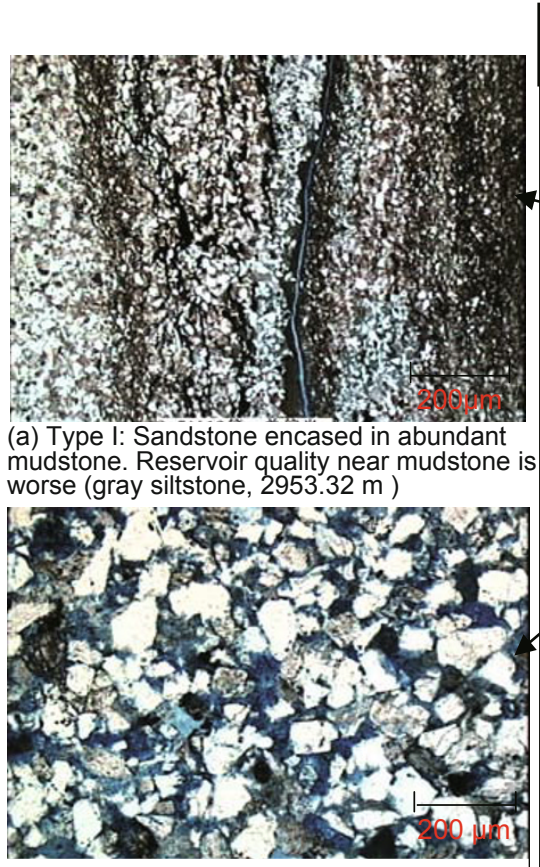

(b) Type I: Sandstone encased in abundant mudstone. Reservoir quality in the middle of sandstone is better (gray sandstone, $2965.32 \mathrm{~m}$ )

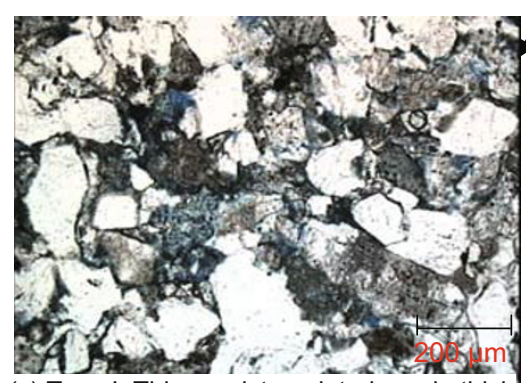

(c) Type I: Thin sandstone interlayer in thick mudstone. Reservoir quality in sandstone is bad (gray sandstone, $2975.87 \mathrm{~m}$ )

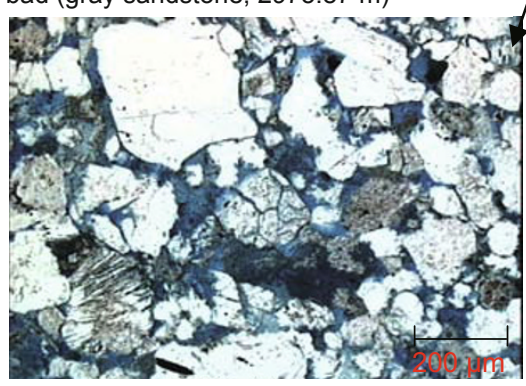

(d) Type II: Mudstone overlying sandstone. Reservoir quality downwardly inner sandstone is getting better (gray sandstone, $2985.87 \mathrm{~m}$ )

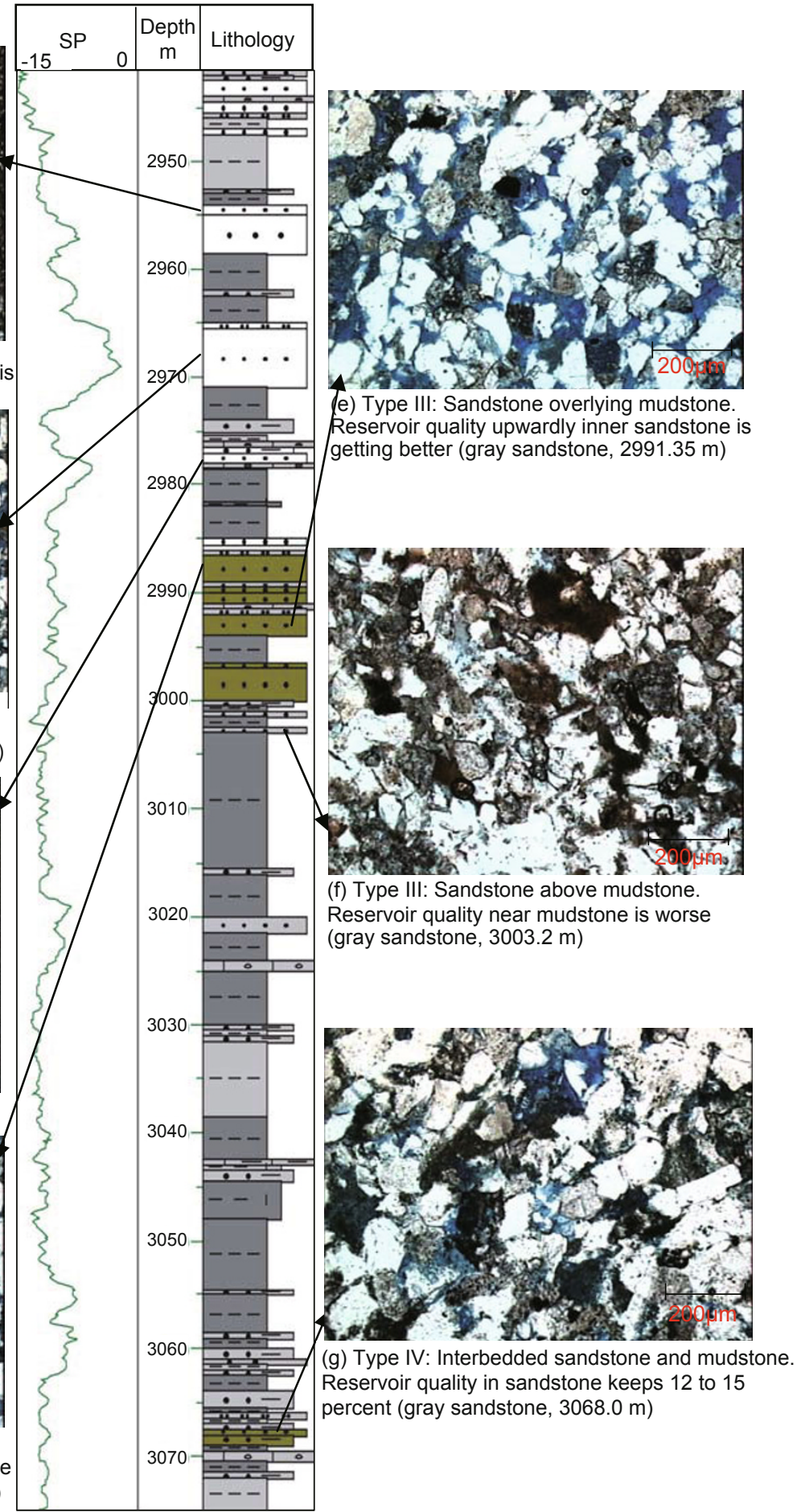

Fig. 9 Reservoir property differences caused by the positions of the sandstone bed in the different sandstone and mudstone successions buried more than 2,500 $\mathrm{m}$ (Well Niu35) 
When the depth is from $800 \mathrm{~m}$ to $1,650 \mathrm{~m}$, interlayer water with $\mathrm{Ca}^{2+}$ ions is discharged from the mudstone and early calcite cement is formed in the surrounding sandstones. The mudstone is still at a sub-mature stage if it contains organic matter, when only limited liquid flow exists at the boundary of the sandstone. During this diagenetic phase, early calcite cementation and weak quartz overgrowth occur in the sandstones, but the interaction of fluids and rocks shows little difference in the middle and boundary parts of a sandstone bed, which leads to weak heterogeneity in the sandstone bed (Fig. 10(b)).

When the depth is from $1,650 \mathrm{~m}$ to $2,500 \mathrm{~m}$, volumes of interlayer water is discharged from the mudstone and organic matter begins to be mature, forming organic acid and $\mathrm{CO}_{2}$ which is expelled. The fluids flow into the adjoining sandstone and cause large-scale dissolution of intergranular carbonate cements and parts of the detrital feldspar grains (Kalia and Balakotaiah, 2009). As a result, the first secondary pore zone is formed. Dissolution is more intense near the boundary of sandstone because of the greater opportunities to react with the acid fluids, resulting in the formation of more secondary pores and hence better reservoir quality as demonstrated in Well Li911 (Fig. 10(c)). However, there is a reverse result in the middle of the sandstone.

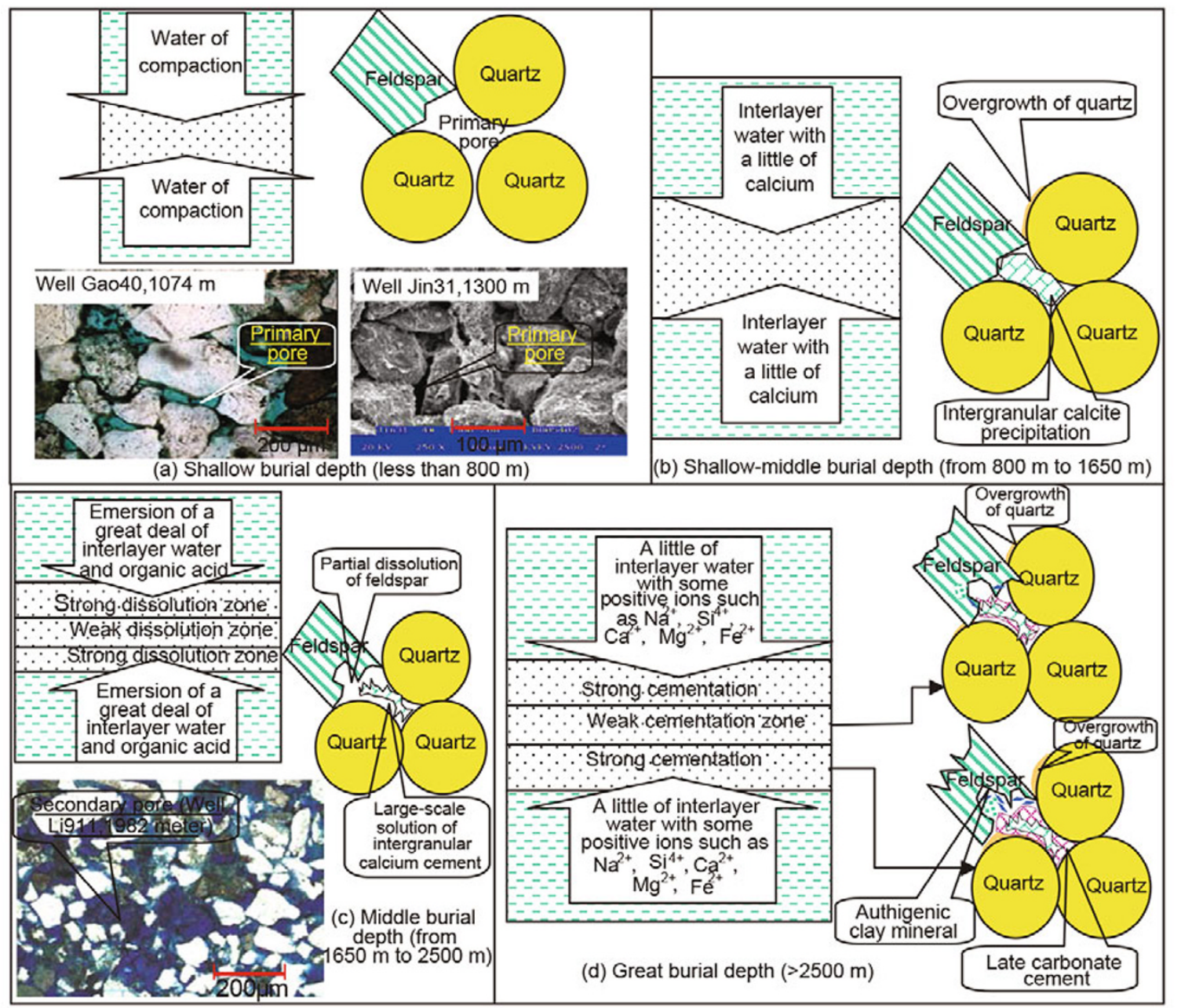

Fig. 10 Mechanisms of reservoir property differences in the sandstone bed caused by different diagenesis occurring in sandstone and mudstone mutual interlayers at different burial depths

When the depth is more than about $2,500 \mathrm{~m}$, the main diagenesis includes the cementation of late carbonates and the precipitation of illite and chlorite. Late cementation is more intense at the boundary of sandstone and thus the porosity is lower than that in the middle part of a sandstone bed (Fig. 10(d)). Take Well Niu35 as an example, at a depth of over 2,500 $\mathrm{m}$, carbonate, clay mineral cementation and quartz overgrowth at the boundary of the sequences of sandstone and mudstone are more intense than those in the middle part of the sandstone bed in any of the vertical sequences of sandstone and mudstone such as sandstone encased in abundant mudstone, sandstone overlying mudstone or vice versa. Thus the reservoir quality tends to be poorer at the boundary than in the middle part.

\subsection{Reservoir quality differences caused by oil saturation}

Charge of hydrocarbon into reservoirs can influence the reservoir quality (Cui et al, 2013). According to thinsection and cathode luminescence observations, oil-bearing 
sandstones are generally less compacted and contain less late stage carbonate cements (Fig. 11(a)), so they tend to have higher porosity. In contrast, water-bearing and dry sandstones are more compacted and of a poorer quality with fewer pores and more late stage carbonate cements (Fig. 11(b)). The higher the oil saturation, the better the reservoir quality.

The above findings can be explained by discussing the influence of hydrocarbon charge into reservoirs on the evolution of diagenesis and porosity (Dong et al, 2008). Based on the analysis of the diagenetic phenomena, the study shows that oil/gas charge does not always terminate

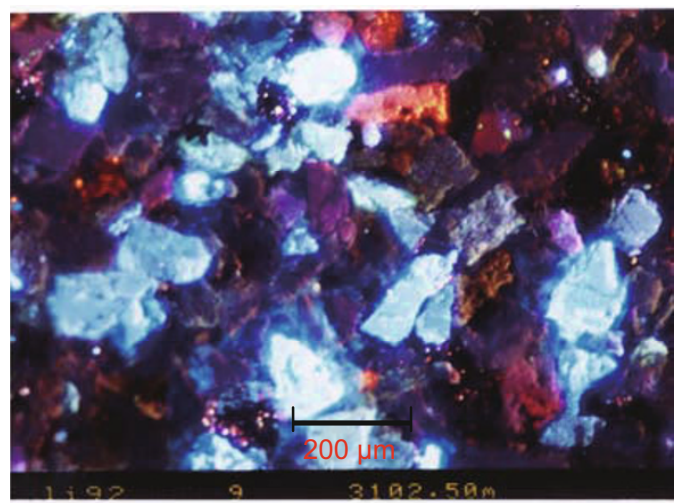

(a) Oil-bearing sandstone with little calcite cement (Well Li92, $3102.5 \mathrm{~m}$ ) diagenesis unless the reservoir is saturated with oil and gas. The charge of oil/gas mainly leads to the following changes of diagenesis: 1) Restrict the cementation of late carbonates; 2) Accelerate the dissolution of feldspar; 3) Prevent the overgrowth of quartz (Molenaar et al, 2007; Kim et al, 2007); 4) Limit the precipitation of authigenic clay minerals, especially illite. As we know that all these diagenetic changes are constructive to the development of secondary pores or the preservation of both the primary and secondary pores present. Therefore the charge of oil/gas into reservoirs will improve the quality of reservoirs as a result.

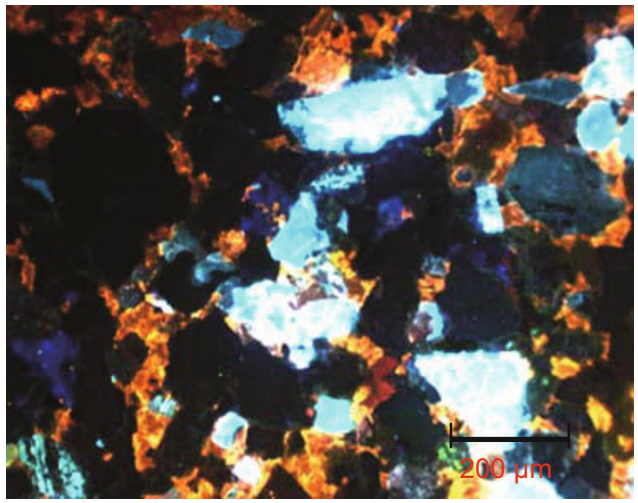

(b) Water-bearing or dry sandstone with much calcite cement (Well Niu35, 2985.87 m)

Fig. 11 Reservoir property comparison in oil-bearing sandstone and water-bearing or dry sandstone (Cathode luminescence photo micrographs)

We use the distribution of illite in different oil saturations as an example to explain the changes of diagenesis when oil/ gas charge occurs (Fig. 12). The maximum content of illite in oil-saturated and oil-immersed sandstones is about $55 \%$, while it is up to over $80 \%$ in oil-spot, oil-trace, fluorescent and water-bearing reservoir sandstones. The findings suggest that, with the increase of oil saturation, the precipitation of authigenic illite will be limited, and thus the pores present will be well preserved. This is why the charge of oil/gas into reservoirs improves the reservoir quality.

\section{Discussion}

In view of the variation of the reservoir quality discussed above and the mechanisms under different conditions, the controlling factors on the clastic reservoir quality in the Dongying Sag are defined clearly, namely depositional condition, diagenesis and tectonic setting. A better understanding of how the depositional environment, evolution of diagenesis and tectonic movement impact the development and preservation of pores is essential for understanding reservoir evolution and for the prediction of favorable reservoirs of the Shahejie Formation in the Dongying Sag.

\subsection{Control of depositional conditions on reservoir quality}

Depositional conditions directly controlled the types of reservoir rocks, their composition, texture and content of the primary pores (Fig. 4), and exercised a further influence on the degree of compaction and the development of late dissolution (Fig. 5), which impacted reservoir quality (Wang and Zhang, 2010; Li et al, 2012). Sedimentary microfacies

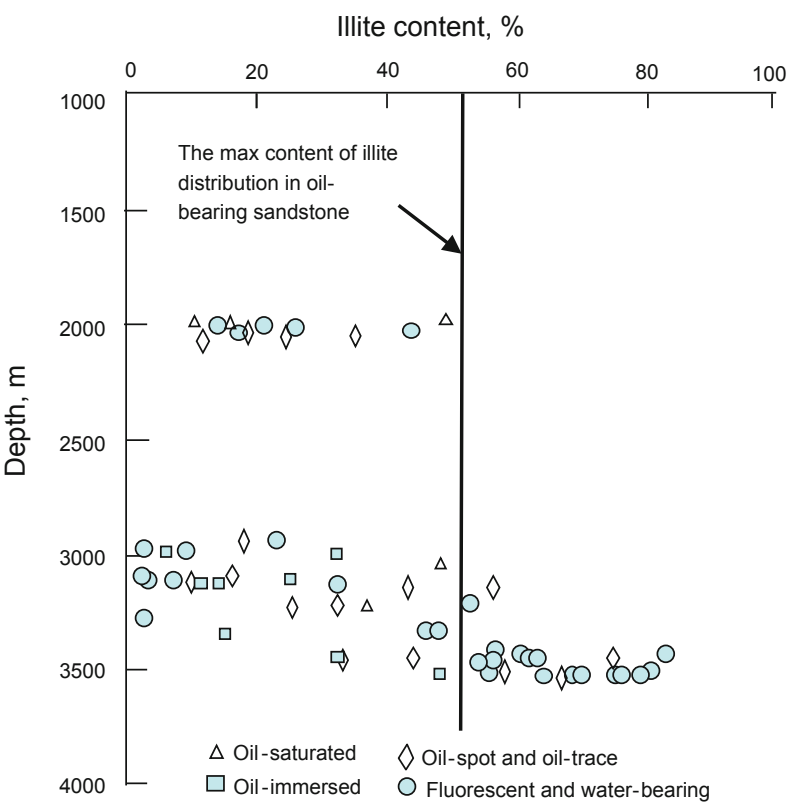

Fig. 12 Distribution of illite in sandstones of different oil saturations 
controlled the lithology and the content of clay and ductile rock fragments which can be deformed easily and squeezed into much of the intergranular pore space in the process of compaction resulting in decrease of the porosity (Zhang et al, 2008). The high energy, well-sorted and relatively coarsergrained distributary channel or front bar sandstones had high primary pores (Fig. 3 and Fig. 4) and during burial they would still be a good conduit for the migration and storage of pore fluids especially for the organic acid water from the mature source rocks contributing to the late dissolution. Therefore, depositional environment is one of the most important controls on reservoir quality because of its influence on the primary pores and the processes of late diagenesis.

\subsection{Control of diagenesis on reservoir quality}

Diagenesis alters the original composition of the sandstones and modifies the porosity and permeability through mechanical compaction and chemical cementation and dissolution (Hakimi et al, 2012; Qiu et al, 2002). The reservoir quality differences in different areas, stratigraphic intervals, oil saturations and positions in a vertical succession of sandstone and mudstone are controlled by different diagenetic evolutions encountered by adjacent reservoir rocks and mudstones. Mechanical compaction is visible from Fig. 6 showing that porosity decreases quickly with increasing burial depth and is more prominent in the early diagenesis stage than in the late stage. Fig. 13 showed the porosity and calcite content were significantly negatively correlated suggesting that cementation and dissolution of calcite controlled the porosity in the Dongying Sag, as well as demonstrated clearly in Fig. 10 and Fig. 11.

In addition, the influence of the model of the vertical succession of sandstone and mudstone and hydrocarbon charge into reservoirs on diagenesis process related to the cementation, dissolution and authigenic clay precipitation resulting in destroying, generating or preserving the pores (Figs. 10, 11, 12,13) showed that the stronger the cementation and the authigenic clay precipitation, the worse the reservoir quality, while the stronger dissolution the reservoirs underwent, the better the reservoir quality.

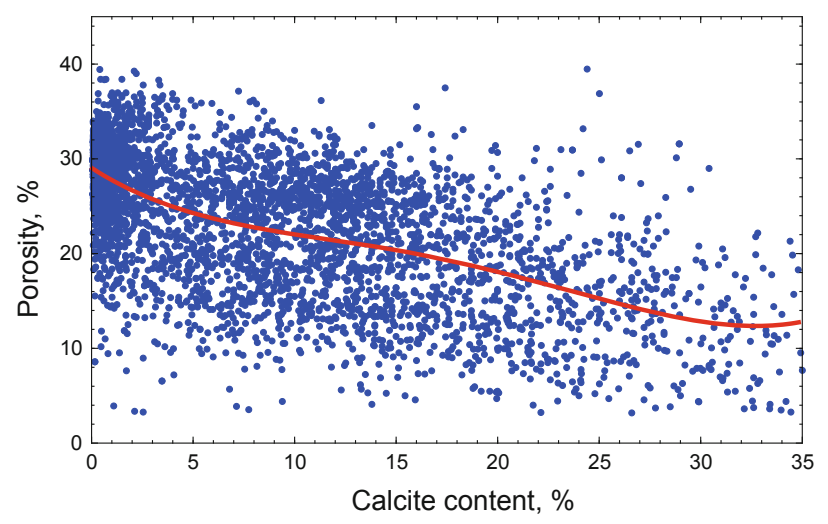

Fig. 13 The relationship of porosity and content of calcite of the Shahejie Formation in the Dongying Sag

\subsection{Control of tectonic setting on reservoir quality}

The control of tectonic setting over the reservoir quality was embodied mainly in controlling the distribution of the sedimentary facies (Khalifa and Morad, 2012) (Fig. 2) which further govern the reservoir rocks and the late diagenesis as above-mentioned and in the improvement of the reservoir properties by active faults. Fault movement favors the flow of fluids in the pores and further influences the dissolution, thereby resulting in the generation of secondary pores. This is one of the principal factors causing the CUZ and NSSZ to have better reservoir qualities than SSZ because of the development of secondary pores resulting from the long period of fault action (Fig. 7).

\subsection{The controls of the reservoir quality of Shahejie Formation}

Based on the analysis above, the reservoir qualities of the Shahejie Formation are mainly controlled by depositional condition, compaction, cementation, dissolution and active faults, which interact with each other and dominate the reservoir qualities together, but their contributions are different (Wang and Zhang, 2010). As we discussed above, the depositional conditions directly dominate the primary porosity and indirectly the processes of late diagenesis ( $\mathrm{Yu}$ et al, 2011). However, if the burial is very deep, the average porosities and permeabilities in the different sedimentary microfacies such as shore-shallow bars, subaqueous distributary channels, sheet sandstone bars and turbidite fan in the same burial depth $2,900 \mathrm{~m}$ to $3,100 \mathrm{~m}$ are about equivalent, which shows that the depositional condition influences the reservoir quality to a certain extent. Reservoir qualities are dominated to a great extent by compaction and cementation. The study of the porosity variation with depth in 6,500 different lithological samples with different carbonate cement contents in the NSSZ shows that carbonate cement content influences the compaction, and the reduced porosity rate decreases with an increase of carbonate cement (Table 2), which implies that the cementation of carbonate favors the preservation of the pores. Dissolution in the Shahejie Formation is the most important control on the reservoir quality. The majority of the reservoirs depend on the secondary pores formed from the dissolution of the early carbonate cement, some of the feldspars and ductile rock fragments except for the reservoirs with more primary pores in $\mathrm{Es}_{2}$ with shallow burial. Therefore, the early carbonate cementation not only provided the materials for the late dissolution but also controlled the process of the dissolution. The fault activity further accelerated the dissolution and the formation of the secondary pores in the CUZ and NSSZ.

As a result, the reservoir quality of the Shahejie Formation is mainly dominated by the early carbonate cementation and late dissolution and influenced by the early compaction. The depositional setting controlled the development of primary pores to some degree and indirectly influenced the process of compaction, cementation and late dissolution. The local fault activity acted as a favorable factor for improving the reservoir quality. 
Table 2 The porosity reduction with depth in different lithology and carbonate cement contents

\begin{tabular}{cccc}
\hline Lithology & $\begin{array}{c}\text { Carbonate cement } \\
\text { content, } \%\end{array}$ & $\begin{array}{c}\text { Reduced porosity rate } \\
\% / \mathrm{km}\end{array}$ & $\begin{array}{c}\text { Number of } \\
\text { samples }\end{array}$ \\
\hline \multirow{3}{*}{ Gritstone } & $<5$ & -11.8 & \\
& $5-10$ & -10.1 & $1500 \pm$ \\
& $10-15$ & -8.9 & \\
Medium & $15-20$ & -19.3 & \\
sandstone & $<5$ & -19.1 & \\
& $10-15$ & -18.3 & \\
& $15-20$ & -12.0 & \\
\hline \multirow{3}{*}{ Fine sandstone } & $<5$ & -12.1 & \\
& $10-15$ & -9.2 & \\
& $15-20$ & -8.6 & \\
\hline
\end{tabular}

\section{Conclusions}

The variation and mechanisms of the clastic reservoir quality in the Shahejie Formation yield important clues to the controls on the reservoir quality:

1) The clastic reservoirs deposited in high energy settings such as fluvial and mouth bar facies have the best reservoir quality due to the depositional conditions embodied as the mechanical control of reservoir configuration and primary porosity and the further chemical influences on the development of secondary pores.

2) The activity of the boundary faults and the sedimentary facies dominate the variation of reservoir quality in different areas and intervals.

3) The reservoir quality varies with the position of sandstone bed in different vertical models of sandstone and mudstone and this arose mainly from the strong cementation or strong dissolution in the sandstone caused by the diagenesis evolution of adjacent mudstone.

4) With higher oil saturation reservoir quality is better because the hydrocarbon charge supports dissolution and restricting cementation.

5) Depositional condition, diagenesis and tectonic setting which interacted with each other constitute the key controls on the reservoir quality of the Shahejie Formation in the Dongying Sag, while carbonate cementation and dissolution are the most important controls.

\section{Acknowledgements}

The research has been financially supported by the National Natural Science Foundation of China (Grant No. ZX20130157), Science Foundation of China University of Petroleum, Beijing (Grant No. KYJJ2012-01-29) and the Key Technologies Research and Development Program of the Chinese Tenth Five-Year Plan (Grant No. 2001BA605A-09). The authors would like to thank Bai Guoping, Sun Xudong and Xing Quanchen from China University of Petroleum (Beijing) and Cornel Olariu from the University of Texas at Austin for their helpful discussion and suggestions in ideas and language.

\section{References}

Büyükutku A G. Diagenesis of Kuzgun sandstones (Middle-Upper Miocene), Adana Basin, Turkey: implications for reservoir heterogeneity. Journal of the Geological Society of India. 2006. 68(4): 615-622

Cui J W, Wang T G, Li M J, et al. Oil filling history of the Bashituo Oilfield in the Markit Slope, SW Tarim Basin, China. Petroleum Science. 2013. 10(1): 58-64

Dong C, O'Keefe M, Elshahawi H, et al. New downhole fluid analysis tool for improved reservoir characterization. SPE Reservoir Evaluation \& Engineering. 2008. 11(6): 1107-1116

Fattahpour V, Moosavi M and Mehranpour M. An experimental investigation on the effect of grain size on oil-well sand production. Petroleum Science. 2012. 9: 343-353

Gier S, Worden R H, Johns W D, et al. Diagenesis and reservoir quality of Miocene sandstones in the Vienna Basin, Austria. Marine and Petroleum Geology. 2008. 25(8): 681-695

Hakimi M H, Shalaby M R and Abdullah W H. Diagenetic characteristics and reservoir quality of the Lower Cretaceous Biyadh sandstones at Kharir oilfield in the western central Masila Basin, Yemen. Journal of Asian Earth Sciences. 2012. 51: 109-120

Hou J G. Prediction of interbeds intercalated into complex heterogeneous reservoirs at a high water cut stage. Petroleum Science. 2007. 4(3): 26-30

Islam M A. Petrophysical evaluation of the subsurface reservoir sandstones in Bengal Basin, Bangladesh. Journal Geological Society of India. 2010. 76(6): 621-631

Jiang Z X, Chen D X and Pang X Q. Control of the formation of lithological reservoirs by surrounding mudstone. Petroleum Science. 2006. 3(2): 1-6

Kalia N and Balakotaiah V. Effect of medium heterogeneities on reactive dissolution of carbonates. Chemical Engineering Science. 2009. 64(2): 376-390

Khalifa M and Morad S. Impact of structural setting on diagenesis of fluvial and tidal sandstones: The Bahi Formation, Upper Cretaceous, NW Sirt Basin, North Central Libya. Marine and Petroleum Geology. 2012. 38(1): 211-231

Kim G Y, Yoo D G, Lee H Y, et al. The relationship between silica diagenesis and physical properties in the East/Japan Sea: ODP Legs 127/128. Journal of Asian Earth Sciences. 2007. 30(3): 448-456

Li J H, Meng Q A, Lu S F, et al. Provenance system analysis of the Nantun Formation of the Huhehu Sag in Hailar Basin. Acta Geologica Sinica (English Edition). 2012. 86(1): 189-198

Li P L. Oil/gas distribution patterns in Dongying Depression, Bohai Bay Basin. Journal of Petroleum Science and Engineering. 2004. 41(1): 57-66

Mallon A J and Swarbrick R E. Diagenetic characteristics of low permeability, non-reservoir chalks from the Central North Sea. Marine and Petroleum Geology. 2008. 25(10): 1097-1108

Mansurbeg H, Morad S, Salem A, et al. Diagenesis and reservoir quality evolution of the palaeocene deep-water, marine sandstones in the Shetland-Faroes Basin, British continental shelf. Marine and Petroleum Geology. 2008. 25(6): 514-543

Marcussen $\emptyset$, Maast T E, Mondol N H, et al. Changes in physical properties of a reservoir sandstone as a function of burial depthThe Etive Formation, northern North Sea. Marine and Petroleum Geology. 2010. 27(8): 1725-1735

Molenaar N, Cyziene J and Sliaupa S. Quartz cementation mechanisms 
and porosity variations in Baltic Cambrian sandstones. Sedimentary Geology. 2007. 195(3): 135-159

Özkan A M and Elmas A. Petrographic and geochemical characteristics of the Kızıloren Formation (Upper Triassic-Lower Jurassic) in the Akpınar (Konya, Turkey) Area. Acta Geologica Sinica (English Edition). 2012. 86(6): 1455-1470

Poursoltani M R and Gibling M R. Composition, porosity and reservoir potential of the Middle Jurassic Kashafrud Formation, northeast Iran. Marine and Petroleum Geology. 2011. 28(5): 1094-1110

$\mathrm{Pu}$ X G, Han W Z, Hua S J, et al. Main controlling factors and dominant reservoir series analysis of $\mathrm{Es}_{3}$ in the Qibei area of Qikou Sag. Acta Geologica Sinica (English Edition). 2013. 87(1): 219-231

Qiu L W, Jiang Z X, Cao Y C, et al. Alkaline diagenesis and its influence on a reservoir in the Biyang Depression. Science in China Series D: Earth Sciences. 2002. 45(7): 643-653

Sun S W, Shu L S, Zeng Y W, et al. Porosity-permeability and textural heterogeneity of reservoir sandstones from the Lower Cretaceous Putaohua Member of Yaojia Formation, Weixing Oilfield, Songliao Basin, Northeast China. Marine and Petroleum Geology. 2007. 24(2): 109-127

Umar M, Friis H, Khan A S, et al. The effects of diagenesis on the reservoir characters in sandstones of the Late Cretaceous Pab Formation, Kirthar Fold Belt, southern Pakistan. Journal of Asian Earth Sciences. 2011. 40(2): 622-635

Wang X M and Zhang S C. Petroleum characteristics and controlling factors in Lunnan Low Uplift, Tarim Basin. Journal of Earth Science. 2010. 21(2): 236-246

Xin R C, Li G F, Feng Z Q, et al. Depositional characteristics of lakefloor fan of Cretaceous Lower Yaojia Formation in western part of central depression region, Songliao Basin. Journal of Earth Science. 2009. 20(4): 731-745

Yu Y X, Chen D X, Pang H, et al. Control of facies and fluid potential on hydrocarbon accumulation and prediction of favorable Silurian targets in the Tazhong Uplift, Tarim Basin, China. Petroleum Science. 2011. 8: 24-33

Zhang J L, Jiang Z Q, Li D Y, et al. Sequence stratigraphic analysis of the first layer, Upper Second Submember, Shahejie Formation in Pucheng Oilfield. Journal of Earth Science. 2009. 20(6): 932-940

Zhang J L, Jia Y and Du G L. Diagenesis and its effect on reservoir quality of the Silurian sandstones, Tabei area, Tarim Basin, China. Petroleum Science. 2007. 4(3): 1-13

Zhang J L, Qin L J and Zhang Z J. Depositional facies, diagenesis and their impact on the reservoir quality of the Silurian sandstones from the Tazhong area in central Tarim Basin, west China. Journal of Asian Earth Sciences. 2008. 33(1): 42-60

Zhang Q, Zhu X M and Li G Q. Heterogeneity of clastic reservoirs of the Shahejie Formation in Dongying Sag and its hydrocarbon significance. Journal of Palaeogeography. 2007. 6(6): 661-668 (in Chinese)

Zhang S W. Application of an integrated approach to the exploration of lacustrine turbidites in Jiyang Sub-basin, Bohai Bay Basin, China. Journal of Petroleum Science and Engineering. 2004. 41(1): 67-77

Zhong D K and Zhu X M. Characteristics and genetic mechanism of deep-buried clastic reservoir in China. Science in China Series D: Earth Sciences. 2008. 51(SII): 11-19

Zhu X M, Dong Y L, Yang J S, et al. Sequence stratigraphic framework and distribution of depositional systems for the Paleogene in Liaodong Bay area. Science in China Series D: Earth Sciences. 2008. 51(SII): 1-10

Zhu X M, Liu C L, Zhong D K, et al. Diagenesis and their succession of gas-bearing and non-gas-bearing reservoirs in the Sulige Gas Field of Ordos Basin, China. Acta Geologica Sinica (English Edition). 2009. 83(6): 1202-1213

(Edited by Hao Jie) 